\title{
Self-Reliance Scale
}

National Cancer Institute

\section{Source}

National Cancer Institute. Self-Reliance Scale. NCI Thesaurus. Code C121290.

A rating scale included in the Behavior Assessment System for Children that measures a

subject's confidence in their ability to solve problems and their dependability and decisiveness. 